\title{
Transitivity and Case Assignment in Ígálâ
}

\author{
Salem Ochala Ejeba \\ University of Port Harcourt, Nigeria
}

\begin{abstract}
Insight on transitivity is derived cross-linguistically in terms of description of formal and functional features in the morphosyntax of token languages. This paper on transitivity and case assignment in Ígálâ describes transitivity in the language from both formal and functional accounts. Structurally, transitive features of a syntactic string are checked off via the ordering of arguments after the verb and features of agreement appear between verbs and their objects to
\end{abstract}

\footnotetext{
$\S$ This is a revised version of a paper presented at the 31st Annual National Conference of the Nigeria English Studies Association (NESA) held 25th-29th October 2015 at Federal University, Lokoja, Nigeria, with the support of the Association of Commonwealth Universities (ACU), London, United Kingdom, which graciously awarded the researcher the Early Careers Academic Grant.

\section{Salem Ochala Ejeba}

Lecturer, Department of Linguistics and Communication Studies, University of Port Harcourt, Nigeria Email: salem.ejeba@gmail.com
}

Received 24 January, 2020; Revised 12 February, 2020; Accepted 11 March, 2020

Copyright (C) 2020 Language Research Institute, Sejong University Journal of Universal Language is an Open Access Journal. All articles are distributed online under the terms of the Creative Commons Attribution Non-Commercial License (http://creativecommons.org/licenses/by-nc/3.0) which permits unrestricted non-commercial use, distribution, and reproduction in any medium, provided the original work is properly cited. 
2 Transitivity and Case Assignment in Ígálâ

validate the object status of arguments in object position. The functional account of transitivity in Ígálâ shows that some technically intransitive verbs may be rendered transitively in causative constructions, causativization being a valency changing and enhancing process in the language. Morphologically, nominal elements in the language are not lexically distinguished for morphological case. On the basis of this observation, this paper ascribes the transitive feature of object to functional properties of verb as governor of object, to check off the syntactic case of this argument.

Keywords: Ígálâ, transitive verb, intransitive verb, valency, case assignment

\section{Introduction}

This paper is a description of transitivity and case assignment in Ígálâ, a West Benue-Congo language spoken majorly in Kogi State, Nigeria by the Ígálâ ethnic group. The language has close affinities with Yoruba and Itsẹkiri languages with which she constitutes the Yoruboid subgroup of languages, according to Akinkugbe (1978) and Capo (1989).

There are two major approaches to the study of transitivity in the linguistic literature: the formal approach and the functional approach. Whereas the formal approach is syntax based with inputs from morphological form, the functional approach is based on the dynamic form-function interrelationship associated with a variety of semantic notions which may be observed to be options of functional features cross-linguistically. Discussion on the form-function approaches is the basis for the description in Sections 2.1 and 2.2. The paper thereafter applies insight from the review in the description of transitivity and case assignment in Ígálâ as contained in Section 3. Section 4 is 
conclusion.

The primary method of data collection for this paper was incidental sampling of the native speaker's speech supplemented by the intuitive knowledge of the researcher as a native speaker of the Dekina variety of Ígálâ. The data presented for analysis use morpheme-by-morpheme mapping of object language to metalanguage structures followed by a translation, in keeping with the Leipzig Convention for interlinear glossing (Max Planck Institute for Evolutionary Anthropology 2015). Representation of the object language utilizes phonetic valued symbols based on International Phonetic Alphabet (IPA).

This paper makes no recurs to a particular theoretical leaning for the analysis of data. However, in showing the derivational patterns in Section 3 using tree diagrams, the analysis applies insights from Chomsky's (1981) Government and Binding model of generative grammar.

\section{The Concept of Transitivity}

Transitivity is the capability of a verb to carry object, particularly the direct object, which usually serves as the complement of the verb (Quirk \& Greenbaum 1973; Radford 1988, 1997; O’Grady 2001). As Agbo (2015: 1) notes, "transitivity is well studied but with attendant controversial issues." According to Katamba \& Stonham (2006: 268), "traditionally, the term transitivity is used to refer to an action initiated by an actor carrying over and affecting another individual, the patient." The patient equates with direct object. Whereas an approach to transitivity is to view it as an inherent property of certain verbs, another holds that transitivity is a dynamic property of verbs in the functional context of syntactic frames. In this latter view, the 
4 Transitivity and Case Assignment in Ígálâ

properties of the verb are defined in terms of its use rather than its inherent morphological property. From a morphological perspective, a strictly transitive verb has properties that ensure that it may not be used without a direct object. Radford (1997: 273) suggests this latter viewpoint in the following statement: "a word is said to be transitive (in a given use) if it checks objective case. For example, hate is a transitive verb in sentences like I hate him because it checks the objective case of him." Thus, even though there seems to be no controversy on the notion of transitivity as a concept or the identification of a transitive verb as a verb that takes at the core a direct object (Finegan 2004, Aarts 2008), a simple categorisation of transitivity in this taxonomic manner would only form a view representational of traditional grammar which makes a binary distinction between transitive verbs such as throw, injure and kiss that take a direct object, and intransitive verbs such as fall or sit that cannot take a direct object.

Transitivity is closely related to valency, which refers to the capacity of a verb to licence arguments and assign theta roles to these arguments in the minimal clause (Payne 1997, Yusuf 1998, Katamba \& Stonham 2006). Payne (1997: 172) provides a typological schema of valency affecting transformations that influence transitivity as in the following:

Valency increasing devices

Those that add a controlling participant: causatives

Those that upgrade a peripherial participant: applicatives possessor raising 
Valency decreasing devices

Those that 'merge' controlling and affected reflexives participants:

reciprocals middles

Those that downplay a controlling participant: subject omission passives inverses

Those that downplay an affected participant: object omission antipassives object demotion object incorporation

With consideration for transitivity in the structure of specific constructions, a further subcategorisation is made of transitive verbs occurring in monotransitive frames and those in ditransitive structures (Quirk \& Greenbaum 1973), representing transitive verbs with two place predicates (monotransitive verbs) and those with three-place predicates (ditransitive verbs) respectively (Katamba \& Stonham 2006: 258). Intransitive, monotransitive and ditransitive verb categories are respectively illustrated in English sentences in (1)-(3) based on Quirk \& Greenbaum (1973: 167, exx. 3, 6, 7). ${ }^{1}$

1 The following abbreviations are used in this paper: ACC (accusative), AgrO/AGR (object agreement), $\mathrm{AGR}_{\mathrm{O}} \mathrm{P}$ (object agreement phrase), $\mathrm{AGR}_{\mathrm{S}}$ (subject agreement), AUX (auxiliary), C (consonant), CL (clitic), DE (deictic enclitic), DIST (distal), ditrans (ditransitive), EMPH (emphatic), G (genitive), intrans (intransitive), INCH (inchoative), MASC (masculine), monotrans (monotransitive), NOM (nominative), NP (noun phrase), O/Obj (object), OBL (oblique), $\mathrm{O}_{d}$ (direct object), $\mathrm{O}_{\mathrm{i}}$ (indirect object), P (pronoun), PASS (passive), PAST (past), PERF (perfective), PL/P1 (plural), S/Subj (subject), SG/Sg (singular), Spec (specifier), $t_{i}$ (trace of moved constituent $\mathrm{i}$ ), $\mathrm{t}_{\mathrm{j}}$ (trace of moved constituent $\mathrm{j}$ ), $\mathrm{t}_{\mathrm{k}}$ (trace of moved constituent $\mathrm{k}$ ), TP (tense phrase), V (verb), VP (verb phrase), 1 (first person), 3 (third person), = (clitic boundary), + (presence of feature), $\theta$ (theta role/argument position), $\varnothing($ deleted/null element), * (ungrammaticality), . (one-to-many metalanguage elements boundary), 
6 Transitivity and Case Assignment in Ígálâ

(1) The child laughed
$\mathrm{S}$

(2) Somebody caught the ball $\mathrm{S} \quad \mathrm{V}_{\text {monotrans }} \mathrm{O}$

(3) She gives me expensive presents $\mathrm{S} \quad \mathrm{V}_{\text {ditrans }} \quad \mathrm{O}_{\mathrm{i}} \quad \mathrm{O}_{\mathrm{d}}$

With data from Iatmul and Barai (languages of Papua New Guinea) as provided by Katamba \& Stonham (2006: 264-265), this paper further illustrates transitivity. Examples (4) and (6) illustrate intransitive verbs in Iatmul and Barai languages respectively whereas (5) and (7) are instances of transitive verbs in the respective languages.

(4) ntiw yi-nti

man go.3SG-MASC

'The man went.'

(5) ntiw takwə vi1-ntiı

man woman see.3SG-MASC

'The man saw the woman.'

(Katamba \& Stonham 2006: 264, ex. i)

(6) e ije ruo

man the come

'The man came.'

[] (phonetic transcription), () (optional element/constituent), ' (high tone), ' (low tone), (rising tone) and ^ (falling tone). 
(7) e ije ame kan-ia man the child hit-3PL 'The man hit some children.'

(Katamba \& Stonham 2006: 265, ex. iii)

\subsection{Formal Analysis of Transitivity}

Considering formal analysis of transitivity, it is observed in the literature that there are instantiations of some languages which mark this property through morphology, as transitive verbs and intransitive verbs behave in distinctive ways. Campana (2000: 10) ${ }^{2}$ observes for Tagalog (Austronesian, Philippines) that transitivity is reflected in word form to the extent that verb morphology indicates underlying transitivity in the appearance of an Object-Topic marker in sentences. The object markers are the suffix -an in (8), the prefix $I$ - in (9) and the infix -in- in (10) respectively.

(8) Anyayh-an mo ang mga istudyante 'Invite the students.'

(9) I-kula nila ang mga damit

'They're going to bleach the clothes.'

(10) K-in-aailanannamin ang tulong ninyo

'We need your help.' (Campana 2000: 10, exx. 8b-d)

2 Campana (2000) does not provide morpheme-by-morpheme glossing of the data. The representation without metalanguage gloss in this paper is therefore original to the literature. 
8 Transitivity and Case Assignment in Ígálâ

Campana (2000: 11) thus concludes that these "object-topic markers are a sign of transitivity", as they are often associated with the objects of simple sentences, which in turn occur only in transitive verb frames.

According to Akmajian et al. (2006: 170), for a language like Japanese, the formal identification of object is also not syntactic but morphological: The suffix - $o$ is attached to the object for identification, just as subject is indicated by the use of the - $g a$ suffix, as in (11):

$$
\begin{array}{lll}
\text { (11) John-ga } \quad \text { hon-o } & \text { yonda } \\
\text { John-Subj book-Obj } & \text { read } \\
\text { 'John read the book.' } &
\end{array}
$$

According to Akmajian et al. (2006), subjects and objects are overtly marked and recognised separately in Japanese. This morphological markings, rather than linear order, are crucial for the identification of one rather than the other syntactic argument. The order of occurrence notwithstanding therefore, the meaning and transitive relationship of the arguments to the verb remain stable.

The language structure of the Tagalog and Japanese-type languages is unlike the situation in Kana (Kegboid, Nigeria) and English in which syntactic order counts in the identification of sentence constituents. It is possible to identify an intransitive verb in English, for example, by attempting to supply it with an appropriate direct object. Whereas in (12a) the intransitive verb, laughed is shown grammatically without an object following the verb, in (12b) the construction is ungrammatical as a result of a following object to the syntactically intransitive verb.

(12) a. She laughed.

b. * She laughed him. 
By virtue of the inability of the verb laughed to take a direct object, it is clear that it is not a transitive verb. This is a fact of syntax besides anything else. The English example is also similar to Kana in which the object of the verb has to occur, ordered after the verb to show that the verb is transitive. Specifically, Ikoro (1996: 206) notes for Kana as follows: "The principal means of indicating grammatical roles of subject and object is word order. Kana is an SVO language. This word order arrangement is very strict." The illustration in (13) comes from Ikoro (1996: 207, ex. 10).
(13) māā kúé ālō
I.PROG call you.EMP
'I am calling you (EMP).'

There are other languages like Korku (an Austroasiatic language of India, Nagaraja 1999) which are in between to the end that syntactic order as well as morphological shape of the interacting words contributes to transitivity. The morphological elements occur in the form of agreement affixes, the verb having number as well as person markers in agreement to the object of the same clause, as in (14).
(14) Iñj Dic-ke bacaTiñ-khe-nec I he-obj save-pt-per 'I saved him.'

(Nagaraja 1999: 99, ex. ii)

Importantly to observation and description of transitivity, Nagaraja (1999: 99) notes that "the feature of agreement will not appear if there is no object" as agreement feature appears only when an object occurs in the minimal clause. This linguistic data from Korku is in tandem with Baker's (1985) Mirror Principle which states that "morphological 
derivations must directly reflect syntactic derivations (and vice versa)" (Katamba \& Stonham 2006: 288).

\subsection{Functional Analysis of Transitivity}

Agbo (2015: 5) takes a functional view of transitivity in asserting that "transitivity is a continuum with clauses at one end of the continuum having high transitivity and at the other end are clauses with low transitivity" based on a scale of morpho-syntactic variables such as valency adjusting operations. The functional analysis of transitivity is therefore justified on the basis that some technically intransitive verbs may be rendered transitively in certain valency adjusting constructions or the other way round, some transitive verbs may become intransitive. Either of these possibilities is obtainable in valency changing transformations such as passivization - a movement operation through which the direct object of a verb becomes the subject and the logical subject is most often lost, rendering a construction intransitive; causativization - an argument insertion process by which the subject of specific construction creates a change in the state of affairs of someone or something else, another argument in the structure; or benefactive construction - a construction in which the argument that serves as beneficiary of the action of a verb is made obvious in a prepositional phrase. According to Pardeshi (2000: 117), these three are under the rubric of voice, which is the expression of the "meaning relationship between core arguments and the action denoted by the verb". This may be observed in the intransitive verbs and their corresponding transitive verbs expressing causative meaning as in (15)-(19) based on Quirk \& Greenbaum (1973: 172, ex. 7.10). 
(15)
a. The door
opened
$\mathrm{S}_{\text {affected }}$
V
b. John/The key
opened
the door
$\mathrm{S}_{\text {agent/instrument }}$
V
$\mathrm{O}_{\text {affected }}$

(16)
a. The flowers
have died
$\mathrm{S}_{\text {affected }}$
$\mathrm{V}$
b. The frost
has killed
$\mathrm{S}_{\text {agent/instrument }}$
V
the flowers
$\mathrm{O}_{\text {affected }}$

(17)
a. The road
became
narrower
$\mathrm{S}_{\text {affected }}$
$\mathrm{V}$
C

b. They
$\mathrm{S}_{\text {agent/instrument }}$

$\begin{array}{ll}\text { narrowed } & \text { the road } \\ \mathrm{V} & \mathrm{O}_{\text {affected }}\end{array}$

(18)

a. I

$\mathrm{S}_{\text {affected }}$

got

angry

V

C

b. His manner

angered

me

$\mathrm{S}_{\text {agent/instrument }}$

V

$\mathrm{O}_{\text {affected }}$

(19)
a. My dog
was walking
Sagentive $\mathrm{V}$
b. I
was walking
$\mathrm{S}_{\text {agentive }}$
V
my dog
$\mathrm{O}_{\text {affected }}$ 
Whereas the sentences in (15a)-(19a) are intransitive with basically intransitive verbs, in corresponding causative constructions in (15b)(19b), the verbs are transitivized. Another instance of causativisation as a valency changing transformation is obtained from Luganda (Katamba \& Stonham 2006: 289). Whereas the non-causative construction in (20a) occurs in the frame of an intransitive verb, the same verb is rendered transitively through causativization in (20b).

(20) a. Abaana basoma
children read
'The children read.'

b. Nnaaki asom-es-a abaana Nnaaki read-CAUS-BVS children

'Nnaaki makes the children read.'

(Katamba \& Stonham 2006: 289, exx. 12.51 a \& b)

A further instance of valency adjusting transformation that affects transitivity is that of passivization which makes the logical object optional. This can be seen in Japanese data based on Payne (1997: 208 ) in which the subject noun phrase (NP) in (21a) is realised as an optional oblique NP, as in (21b).
(21)
a. Taro-ga
Hanako-o
nagut-ta
Taro-NOM
Hanako-ACC
hit PAST
'Taro hit Hanako.' 


\section{b. Hanako-ga (Taro-ni) nagu-rare-ta Hanako-NOM (Taro-OBL) hit-PASS-PAST 'Hanako was hit by Taro.'}

(Payne 1997: 208, exx. 94 a \& b)

Valency changing operations like the ones demonstrated above make Katamba \& Stonham (2006: 272) conclude that "one major determiner of the $\theta$-roles which hold between a verb and its arguments is the meaning of the verb" and "this shows clearly that it is the particular sense of the verb which largely determines the $\theta$-roles which obtain between the verb and its arguments." $\theta$-roles (theta-roles are thematic roles - the semantic roles played by arguments in relation to their predicates (Radford 1997: 273)). What this means is that the actual nature of a verb's transitivity is after all NOT dependent on the verb's inherent characteristics as a designated type-transitive or intransitive, as it would have been if the phonetic, morphological and lexical characteristics of a verb were solely sufficient to determine the frame within which a verb may function. Rather than concentrating on the inherent properties of the verb in isolation for proof of transitive features therefore, the actual nature of a verb's transitivity is to a great extent estimated within its dynamic situation in a clause nexus as a FUNCTIONAL system of various syntactic processes. These syntactic processes are causativisation, passivization and antipassivization, as well as numerous other processes attested in natural language.

On the basis of this review, this paper finds sufficient leverage for certain premises, based on Katamba \& Stonham (2006: 267ff) and generally in the literature:

(a) Certain semantic relations are signified by theta-roles or abstract case relations representing referring expressions, 
arguments (constituents which indicate individuals or entities) to hold between the verbs as predicates and the arguments. Thus, Katamba \& Stonham (2006: 270) note generally that "In order to ensure that a verb appears in the right syntactic frame, the lexicon must specify the $\theta$-roles which it requires."

(b) The theta-roles are essentially recognised as a relatively small number of syntactically relevant semantic properties used to characterise the transitivity system of languages, specifying the part played by arguments representing different participants in the action, state or process indicated by the verb.

(c) It is the dynamic sense of the verb which largely determines the theta-roles which hold between a verb and its arguments, for which reason theta-roles change from verb sense to verb sense rather than from verb to verb. Yusuf (1998: 8) thus expands the lexical properties of a ditransitive verb, 'kill' as follows;

$$
\text { Kill; V, + [_ NP] <AGENT, PATIENT> }
$$

(d) Arguments are independent variables corresponding to NP positions within the sentence (Horrocks 1987, Radford 1988, Ndimele 1992) specified by theta-roles in the predicate structure of verbs.

(e) Verbs are predicates which can occur in frames with one, two or three arguments. Intransitive verbs are one-place predicate structures, transitive verbs are two-place and ditransitive verbs are three-place. Katamba \& Stonham (2006: 270) identify several ditransitive verbs which may be distinguished through their $\theta$-roles, which are encoded by the rules of the grammar of various natural languages. They include the following;

i. Verbs of giving such as give, send, lend, post which have 
agent, goal and theme.

ii. Verbs of placing such as place, put, position, deposit which require an agent, a theme and a locative. And,

iii. Instrumental verbs which require an agent, a patient and an instrument.

This paper shall proceed with insight from the various opinions in the literature to account for transitivity and case assignment in Ígálâ.

\section{Transitivity in Ígálâ}

Basically, transitivity in Ígálâ is syntactically realized, as there are no special morphological marking for transitive elements in sentences. Since the language is an SVO language (Ejeba 2008), the subject always occurs at the beginning of a sentence and where the object occurs, it comes immediately after the verb. Thus the principal means of indicating these basic grammatical roles is word order. There are instances of one-place, two-place and three-place predicate structures in Ígálâ. The one-place predicates are intransitive verbs with only the subject of the sentence, as in (22)-(24):

(22)

$\begin{array}{ll}\text { ábiá }=\text { mi }=1=1 & \text { lèk }^{\text {wú }} \\ \operatorname{dog}=1 \mathrm{SgGCL}=\mathrm{SCL} . \mathrm{PERF}=\mathrm{AUX} & \text { dead } \\ \text { 'My dog is dead.' } & \end{array}$

(23) j́kว́ òdzòrú kpó tínô

money Ojoru INCH throw.away

'Ojoru's money is missing.' 

(24) j́ma=nwu á ní àní child=3SgGCL AUX laugh laughter 'His/her child is laughing.'

In Ígálâ transitive frame, the verb necessarily occurs with an object, specifically the direct object. Observe this fact in the occurrence of the transitive verbs in (25)-(26).

(25)
a. du úgbá=lè carry.SG plate $=\mathrm{DE}$ 'Carry that plate.'

b. kó úgbá $=1 \grave{\varepsilon}$ carry.PL plate $=\mathrm{DE}$ 'Carry those plates.'

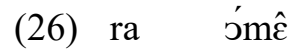
pay debt
'Pay the debt.'

Particularly in (25a) and (25b), it may be noticed that there is the feature of agreement between the verbs and their objects as the gloss and translation reveal: Singular verb attracts singular object in (25a) and plural verb attracts plural object in (25b). This feature of agreement may serve as argumentation for the presence of transitivity, as if there were no object, there would have been no agreement between the verb and object. There are other constructions in which the verb may require two objects. These latter are ditransitive verbs as (27)-(30) illustrate: 
(27) kpé àmădê útf́́

send Amade message

'Send Amade.'

(28) dà àmădê ìòtó

snap Amade picture

'Snap Amade.'

(29) mé àmădê jókó

lend Amade money

'Lend Amade some money.'

(30) ódzí gbà àmădê j́kó

thief take Amade money

'Thieves stole Amade's money.'

\subsection{Influence of Valency Changing Transformation on Transitivity in Ígálâ}

Valency changing operations, particularly the case of causativisation has significant consequences on an adequate understanding of transitivity in Ígálâ. Like the cases of English and Luganda demonstrated earlier in Section 2.2, causative formation in Ígálâ as in (31b)-(32b) derived from (31a)-(32a) is an instrumental strategy for the intransitive relationship that exists between certain Ígálâ verbs and their arguments in the basic clause to be dynamically influenced for the causative verb to reassign $\theta$-roles within the functional system of the language. The result of this structural change is that the otherwise intransitive verbs are realized as transitive verbs. Thus, in (31b) and (32b) the causative structures warrant the introduction of new agentive NPs at the subject positions of the clauses. The original 
subjects in (31a) and (32a) therefore become the objects of their respective structures whereas the original verbs change to the causative verbs, che 'do' and kpa 'kill' in (31b) and (32b) respectively. There is a corresponding expansion in the distribution of the semantic roles that the arguments of the causative verbs are deployed to play in the causative constructions.
(31)
$\begin{array}{rlll}\text { a. àmădê } & \text { á } & \text { lè } & \text { ólu } \\ \text { Amade } & \mathrm{AUX}^{3} & \text { sleep } & \text { sleep }\end{array}$
'Amade is sleeping/Amade will sleep.'
$\begin{array}{lllll}\begin{array}{l}\text { b. ógwù=lé } \\ \text { medicine=DE.DIST }\end{array} & \text { á } & \text { che àmădê } & \text { ólu } \\ \text { do } & \text { Amade } & \text { sleep }\end{array}$
'The drug has caused Amade to sleep/The drug will cause Amade sleep.'

3 The á form is the basic auxiliary element in Igala called 'the primary auxiliary' in the literature (Ejeba 2016: 90). This auxiliary cannot be said to be a progressive, future or perfective marker in the language. As the glosses show, the sentence in (31a) may be interpreted either as progressive or future expression whereas the sentence in (31b) may be interpreted either as perfective or future expression. For this reason of diverse aspectual interpretation when the primary auxiliary is involved, this auxiliary is not shown to indicate a distinct aspectual structure. Thus, whereas àmădê á lè ólu 'Amade is sleeping/Amade will sleep', for instance with the primary auxiliary has at least two different interpretations as the gloss shows, àmădê náá lè ólu 'Amade was sleeping', àmădê á nálè ólu 'Amade will sleep' are each clearly progressive and future expressions respectively where the primary auxiliary forms a complex with the progressive auxiliary, $n a^{\prime}$ for progressive expression and with the future auxiliary, na for future expression. Whereas Ejeba (2016) outlines this much in the description of Igala auxiliary, the need exists for further research into the nature of tense, aspect, mood and existentiality in Igala to explicate the complex relationship of the auxiliary elements with verbal and clitic elements in their vicinity. 

a. àmădê ní àní
Amade laugh laughter
'Amade laughed.'
b. àwa $=$ à $\quad \mathrm{kpa}$ àmădê àní
1PIS=1PISCL kill Amade laughter
'We made Amade laugh.'

This demonstration above makes Katamba \& Stonham's (2006: 272) conclusion to hold sway that "it is the particular sense of the verb which largely determines the $\theta$-roles which obtain between the verb and its arguments."

\subsection{Case Assignment Possibilities and Transitivity}

Unlike the case of English where all the personal pronouns are morphologically marked for Case except for the third person pronouns; In Ígálâ, as earlier mentioned, there is no way to determine a subject from an object noun, except by placement in syntactic context. This fact is consistent with that of pronouns. Thus, the personal pronouns - òmi ' $\mathrm{I} / \mathrm{me}$ ', àwa 'we/us', ùwe 'you (sg)', àme 'you (pl)' ò "u 's(he)/her/him' and àma 'they/them' are simply not lexically distinguished for morphological case. This however offers an avenue for argumentation for transitivity revealed in the function of the verb as governor of object, to mark this argument for syntactic Case. This case is made for transitivity in Belletti (2001: 489), "Much as nominative Case is checked in Spec/AgrS of finite tensed clauses under the 'agreement' relation, so accusative is checked in Spec/AgrO of clauses containing a transitive verb."

The pronoun with inherently unmarked case, when it is in object position, is Case marked in the objective or accusative Case. 
Following Chomsky's argument that "NP is objective if governed by V with the subcategorization feature: _ NP" (Chomsky 1965, Ura 2001: 336), the objective Case would be assigned to the NP simply as an internal argument of V. On another hand however, Gerlach \& Grijzenhout (2000) and Belletti (2001) explain that AgrO is another position for Case assignment. If indeed their assertions are true, and if indeed, on the other hand, the object NP is Case marked by the Case assigner $\mathrm{V}$ at an earlier stage; there would seem to be a conflict in opinion as to the Case marking reality and relation of the object of a minimal clause.

Campana (2000: 6) much consents to this latter view in the analysis of underlying transitivity, considering Case assignment relations in Tagalog, a language with a nominative-accusative Case system: "AgrS is responsible for checking the nominative Case features of the subject (NP1), while AgrO checks the accusative Case features of the object (NP2)." Thus Belletti upholds that Agr head uniformly mediates Case assignment under nominal relations. While it is true that accusative is a property of the verb associated with its transitivity, as observed in the general conception of clause structure; The conflict of the generalized structure with what Belletti conceives (which this research work shall prove to be compatible with the facts of Ígálâ) would only be in the process to the derivation.

Belletti (2001: 489) predicts the process suitable for the analysis of Ígálâ in two important statements: (i) To the extent that Case features of a transitive verb is checked through head movement of the verb into AgrO, $\mathrm{V}$ must be assumed to move out of the verb phrase (VP) in all languages, at least as far as AgrO; And (ii) if accusative Case on the object is checked in Spec/AgrOP, this implies that object should also move out of VP. This object movement hypothesis is a departure from the standard assumption that it is only the 'VP-internal Subject' that 
moves to be properly checked. Following Belletti's suggestions therefore, this paper assumes that the verb first moves to $\mathrm{Agr}_{\mathrm{o}}$ from its underlying position, to check off its transitive features; From where it moves to the higher $\operatorname{Agr}_{\mathrm{s}}$ which is an ultimate landing site for $\mathrm{V}$. Object NP is also raised out of VP to the Specifier of $\operatorname{Agr}_{0} \mathrm{P}$, where it is now in the vicinity of the raised verb, for the assignment of accusative Case, otherwise, the structural properties of the NP is not specified as objective (Collins 2001).

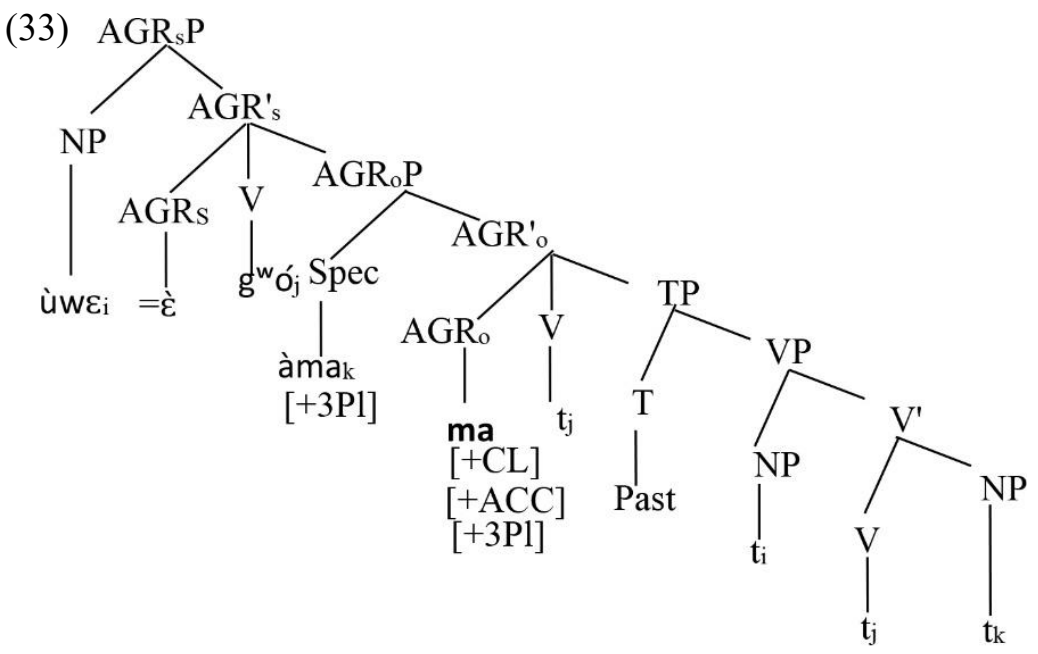

ùw $\varepsilon=\grave{\varepsilon} g^{w} o^{a}$ àma

'You flogged them.' (EMPH)

As in (33), this paper presents argumentation for these assertions from the facts of co-occurrence restriction of objects and object clitics as opposed to the licensing of such a co-occurrence at subject position. The object clitic element, ma in AgrO position is in bold and without 
tone on the tree structure to show lack of appropriate phonetic realization since it is not possible in the language for the object and object clitic elements to co-occur in the same minimal clause.

At the point of object NP being raised out of VP, the object clitic is juxtaposed with the object NP from which it copies the appropriate nominal features, as (33) shows. The co-occurrence restriction between the object NP and the object clitic results since the object clitic is base-generated as head of $\mathrm{Agr}_{0}$ and does not absorb the role of argument nor share a Case relationship with object NP. It is therefore simply co-indexed with the object NP position by chain coindexing as a clitic realization rule. The semantic restriction on their co-occurrence is explainable with the invocation of Suñer's (1988) 'Matching Principle', as expressed in Gerlach \& Grijzenhout (2000: 21): "Clitics and NPs in the same chain must have identical agreement features and this thus restricts their co-occurrence."

In pro-drop situation in overt syntax however, the object clitic obtains the agreement features of the object NP by the Matching Principle and surfaces as the morphologically reduced counterpart of object Pronoun, in the accusative Case associated with the $\operatorname{Agr}_{0}$ position. On the surface realization, the clitic forms a complex with $\mathrm{V}$ by which interaction it is assigned the functional tone. Example (34) illustrates this situation in the minimal clause: 


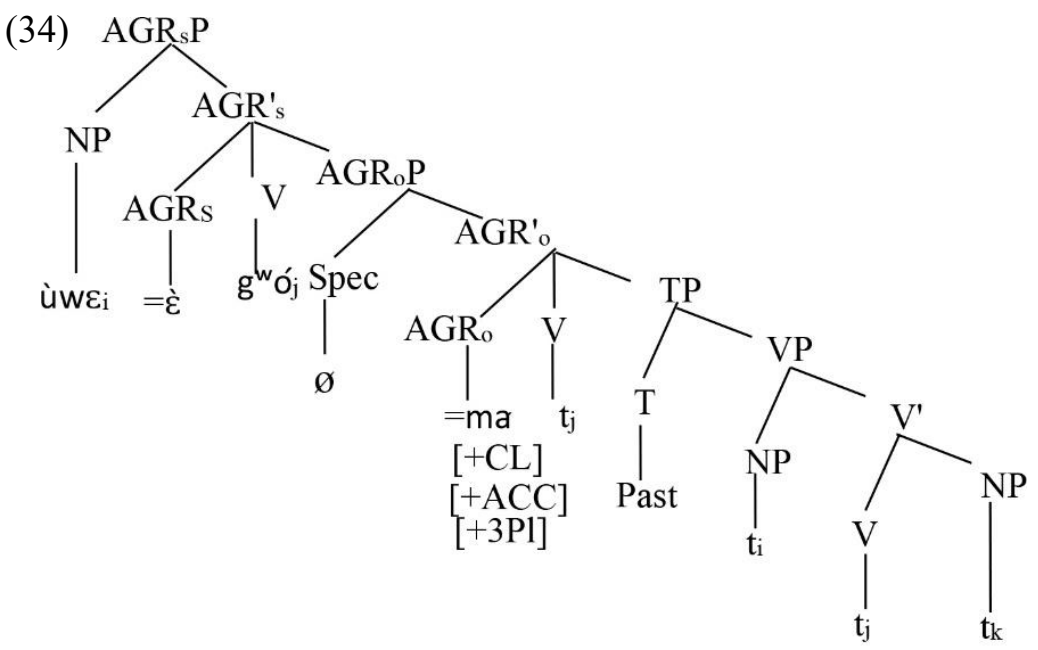

ùw $\varepsilon=\grave{\varepsilon} \mathrm{g}^{\mathrm{w}} \mathrm{ó}^{=} \mathrm{má}$

'You flogged them.'

\section{Conclusion}

There are two major views on the nature of transitivity. Whereas one view holds that a verb is either transitive or intransitive, the other posits that transitivity is a matter of degree, based on the functional relations established in language use. This paper on transitivity and Case assignment in Ígálâ utilized aspects of the two views in arriving at an adequate descriptive account. The paper accounted for the structural properties of Ígálâ transitivity as the syntactic ordering of arguments after the verb with features of agreement appearing between verbs and their objects. This serves to validate the treatment of certain elements rather than some others as objects. The functional account on the other hand showed that some intransitive verbs may 
24 Transitivity and Case Assignment in Ígálâ

become transitive in causative construction, causativity being a valency changing process. The paper proceeds to explain transitivity in terms of Case assignment, arguing for the verb as a functional element that assigns Case to objects. 


\section{References}

Aarts, B. 2008. English Syntax and Argumentation. 3rd edition. London: Palgrave Macmillan.

Agbo, M. 2015. Causativity and Transitivity in Igbo. Journal of Universal Language 16.2, 1-25.

Akinkugbe, F. 1978. A Comparative Phonology of Yoruba Dialect, Isekiri and Ígálâ. Ph.D. Dissertation, University of Ibadan.

Akmajian, A. et al. 2006. Linguistics: An Introduction to Language and Communication. 5th edition. New Delhi: Prentice-Hall of India Private Limited.

Baker, M. 1985. The Mirror Principle and Morphosyntactic Explanation. Linguistic Inquiry 16.3, 373-415.

Belletti, A. 2001. Agreement Projection. In M. Baltin \& C. Collins (eds.), The Handbook of Contemporary Syntactic Theory 483510. Malden, MA: Blackwell.

Campana, M. 2000. Underlying Transitivity in Tagalog. In R. Kikusawa \& K. Sasaki (eds.), Modern Approaches to Transitivity 1-28. Tokyo: Institute for the Study of Languages and Cultures of Asia and Africa.

Capo, H. 1989. Defoid. In J. Bendor-Samuel (ed.), The Niger Congo Languages 275-290. Lanham \& London: University Press of America.

Chomsky, N. 1965. Aspects of the Theory of Syntax. Cambridge, MA: MIT Press.

Chomsky, N. 1981. Lectures on Government and Binding. Dordrecht: Foris.

Collins, C. 2001. Economy Conditions in Syntax. In M. Baltin \& C. Collins (eds.), The Handbook of Contemporary Syntactic Theory 45-61. Malden, MA: Blackwell. 
Ejeba, S. 2008. Noun-Modifier Relations in Ígálâ as a Response to Basic Word Order. Journal of the Linguistic Association of Nigeria 11.1, 145-150.

Ejeba, S. 2016. A Grammar of Ígálâ. Port Harcourt: M\&J Grand Orbit Communications.

Finegan, E. 2004. Language: Its Structure and Use. 4th edition. Boston, MA: Wadsworth.

Gerlach, B. \& J. Grijzenhout. 2000. Clitics from Different Perspectives. In B. Gerlach \& J. Grijzenhout (eds.), Clitics in Phonology, Morphology and Syntax 1-29. Amsterdam: John Benjamins.

Horrocks, G. 1987. Generative Grammar. London: Longman. Ikoro, S. 1996. The Kana Language. Leiden: Research School CNWS. Katamba, F. \& J. Stonham. 2006. Morphology. 2nd edition. New York: Palgrave Macmillan.

Max Planck Institute for Evolutionary Anthropology. 2015. The Leipzig Glossing Rules: Convention for Interlinear Morphemeby-Morpheme Glosses. Available at <http://www.eva.mpg.de/ lingua/resources/glossing-rules.php $>$.

Nagaraja, K. 1999. Korku Language: Grammar, Texts, and Vocabulary. Tokyo: Institute for the Study of Languages and Cultures of Asia and Africa.

Ndimele, O. 1992. The Parameters of Universal Grammar: A Government-Binding Approach. Owerri: African Educational Services.

O'Grady, W. 2001. Syntax: The Analysis of Sentence Structure. In W. O'Grady et al. (eds.), Contemporary Linguistics: An Introduction 183-244. 4th edition. Boston, MA: Bedford/St Martin's.

Pardeshi, P. 2000. Transitivity and the Causative in Marathi. In R. Kikusawa \& K. Sasaki (eds.), Modern Approaches to Transitivity 
115-139. Tokyo: Institute for the Study of Languages and Cultures of Asia and Africa.

Payne, T. 1997. Describing Morphosyntax: A Guide for Field Linguists. Cambridge: CUP.

Quirk, R. \& S. Greenbaum. 1973. A University Grammar of English. Harlow: Pearson Education.

Radford, A. 1988. Transformational Grammar: A First Course. Cambridge: CUP.

Radford, A. 1997. Syntax: A Minimalist Introduction. Cambridge: CUP.

Suñer, M. 1988. The Role of Agreement in Clitic-Doubled Constructions. Natural Language \& Linguistic Theory 6, 391-434. Ura, H. 2001. Case. In M. Baltin \& C. Collins (eds.), The Handbook of Contemporary Syntactic Theory 334-373. Malden, MA: Blackwell.

Yusuf, O. 1998. Fundamentals of Syntax and the Study of Nigerian Languages. Ijebu-Ode: Shebiotimo Publications. 